Richard C. Etches MD FRCPC

\section{Respiratory depression associated with patient- controlled analgesia: a review of eight cases}

l'apparition de cette complication. Avec cet objectif en vue, le bureau médical de l'amélioration de la qualité a recherché rétrospectivement les cas de dépression respiratoire dans une banque de données compilées à partir des dossiers de 1600 patients traités par PCA dans les hôpitaux de l'université de l'Alberta en 1992. On a retracé huit cas de dépression respiratoire grave. Les facteurs associés avec la survenue de cette dépression comprenaient l'administration concomitante d'une perfusion continue ou de sédatifs, la vieillesse et la pré-existence du syndrome d'apnée du sommeil. Des erreurs humaines ou instrumentales n'ont jamais été mises en cause. Pour conclure, le risque d'une dépression respiratoire avec la $P C A$ morphinique est le même que celui qu'on retrouve avec les morphiniques im ou rachidiens. La sécurité et l'efficacité de l'analgésie autocontrôlée dépend d'un personnel soignant et médical avisé, de politiques et protocoles bien établis et d'une surveillance étroite.

The use of patient-controlled analgesia (PCA) for the management of postoperative pain has grown rapidly. Patient-controlled analgesia is often presented as an effective alternative to traditional im opioids without the complexity of and concern for respiratory depression associated with epidural opioid administration. Few would argue against the effectiveness of PCA, out there is little evidence to support an argument that the risk of severe respiratory depression is less than with epidural opioids. In fact, the limited data suggest that the incidence may be greater with PCA than with epidural opioid admin-

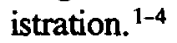

This paper reviews eight cases of severe respiratory depression occurring in patients receiving PCA at the University of Alberta Hospitals.

\section{Methods}

Description of the acute pain management service

The University of Alberta Hospitals has an established acute pain management service (APMS) which cares for approximately 2500 patients annually. Most are adults undergoing major orthopaedic or general surgical procedures, and approximately $80 \%$ receive PCA postopera- 
tively. The APMS is staffed by a dedicated staff anaesthetist who provides the service on a weekly basis and is on $24 \mathrm{hr}$ call during that week. This individual sees patients preoperatively and daily (including weekends and holidays) following surgery until the patients no longer require parenteral analgesics. At night, calls are initially taken by the anaesthesia residents; if the resident wishes, he/she may contact the staff anaesthetist. With the exception of a single intensive care unit, PCA is prescribed and managed by the anaesthesia staff and residents only. The hospital employs a nurse specialist who oversees nursing in-service education and development of the necessary nursing policy and procedures associated with PCA. The hospital uses preprinted PCA order sheets. Opioids for PCA are supplied in two standard preparations, morphine $2 \mathrm{mg} \cdot \mathrm{ml}^{-1}$ and meperidine 20 $\mathrm{mg} \cdot \mathrm{ml}^{-1}$. The dose and lockout interval are left to the discretion of the anaesthetist. Background infusions are used in a small minority of patients. The Graseby PCAS patient-controlled infusion device is used throughout the hospital.

\section{Data collection}

This paper reviews all cases of severe respiratory depression in adult orthopaedic and general surgical patients receiving PCA from January, 1992 until March, 1993. This was accomplished with the support of the Office of Medical Quality Improvement (MQI). The charts of all adult orthopaedic and general surgical patients are reviewed by MQI at the time of admission, $72 \mathrm{hr}$ after admission, and within two weeks following discharge. All adverse patient occurrences are noted and entered into the MQI database. Such occurrences are deemed to have occurred if they appear anywhere in the patient's chart, including the nursing notes, physicians' notes, or other consultations. The Office of Medical Quality Improvement does not attempt to determine the validity or severity of the occurrence; nor is there any assignment of responsibility. Adverse occurrences are brought to the attention of the relevant departmental representatives who analyze the events in detail.

For this paper, MQI searched a database compiled from the charts of approximately 1600 patients. The search criteria were respiratory depression associated with anaesthesia. (All PCA on the orthopaedic and general surgical wards is prescribed and monitored by an anaesthetist.) Charts for these patients were reviewed by the author. It should be noted that this search strategy may overlook patients in whom PCA was temporarily discontinued or changed because of sedation or respiratory depression which the nurse or physician felt was important but not immediately dangerous.

\section{Results}

The Office of Medical Quality Improvement detected eight patients meeting the defined criteria. Three additional patients, not in the MQI database, were brought to the attention of the author by the surgical staff. All 11 patients had a diagnosis of opioid-induced respiratory depression, all were receiving PCA morphine, and all received at least one dose of naloxone. Following a review of the charts, three patients were excluded from further discussion because the severe respiratory events occurred early in the postoperative period, before the patients had received any opioids via the PCA device. Relevant data for the remaining eight patients are summarized in the Table. All patients recovered uneventfully. To date, we are not aware of any deaths or long-term adverse sequelae attributable to the use of PCA in our institution.

\section{Case reports}

\section{Case \#I}

A 52-yr-old man in general good health underwent an uneventful total hip arthroplasty. During the procedure the patient received morphine $9.5 \mathrm{mg}$ and fentanyl 200 $\mu \mathrm{g}$. Patient-controlled analgesia with morphine was started in the post-anaesthetic recovery room (PARR) with a background infusion of $1 \mathrm{mg} \cdot \mathrm{hr}^{-1}$ and a bolus dose of $1 \mathrm{mg}$. Approximately two hours after the initiation of PCA the patient was found on the ward unresponsive with a respiratory rate of four breaths per minute. The patient had received approximately $7 \mathrm{mg}$, PCA morphine. The patient was treated with oxygen by mask and naloxone $0.8 \mathrm{mg} i v$ and recovered immediately. He was subsequently managed with im morphine.

\section{Case \#2}

A 42-yr-old man in general good health underwent an uneventful appendicectomy and subsequently received PCA morphine ( $2 \mathrm{mg}$ bolus and a $1 \mathrm{mg} \cdot \mathrm{hr}^{-1}$ background infusion). Over the next $28 \mathrm{hr}$ the patient received approximately $61 \mathrm{mg}$ morphine, of which $28 \mathrm{mg}$ were delivered by a background infusion. Twenty-four hours after surgery the patient was noted to be confused and drowsy. Pulse oximetry revealed a $\mathrm{SpO}_{2}$ of $59 \%$. The background infusion was discontinued and the patient received oxygen by nasal prongs. Two hours later the patient was confused with a $\mathrm{SpO}_{2}$ of $68 \%$ despite the administration of oxygen by nasal prongs. Respiration was charted as shallow with a respiratory rate of 32 breaths $/ \mathrm{min}^{-1}$. Arterial blood gas analysis revealed $\mathrm{PaO}_{2}$ $46 \mathrm{mmHg}, \mathrm{PaCO}_{2} 55 \mathrm{mmHg}$, and $\left[\mathrm{H}^{+}\right] 55 \mathrm{nmol} \cdot \mathrm{L}^{-1}$ (pH 7.25). The patient was treated with naloxone $0.4 \mathrm{mg}$ iv and recovered uneventfully. Patient-controlled analge- 
TABLE Respiratory depression with PCA

\begin{tabular}{|c|c|c|c|c|c|c|c|c|c|c|}
\hline \multirow[b]{2}{*}{$\begin{array}{l}\text { Case } \\
\#\end{array}$} & \multirow[b]{2}{*}{ Age } & \multirow[b]{2}{*}{ Sex } & \multirow[b]{2}{*}{ Procedure } & \multirow[b]{2}{*}{$\begin{array}{l}\text { Pre-existing } \\
\text { medical factors }\end{array}$} & \multicolumn{3}{|c|}{ PCA Morphine } & \multirow[b]{2}{*}{$\begin{array}{l}\text { Other } \\
\text { Medications }\end{array}$} & \multirow[b]{2}{*}{ Presentation } & \multirow[b]{2}{*}{ Treatment } \\
\hline & & & & & $\begin{array}{l}\text { Bolus } \\
\text { (mg) }\end{array}$ & $\begin{array}{l}\text { Lock- } \\
\text { out } \\
\text { (min) }\end{array}$ & $\begin{array}{l}\text { Back- } \\
\text { ground } \\
\left(m g \cdot h r^{-1}\right)\end{array}$ & & & \\
\hline 1 & 52 & $\mathbf{M}$ & $\begin{array}{l}\text { Total hip } \\
\text { replacement }\end{array}$ & None & 1 & 10 & 1 & None & $\begin{array}{l}\text { Unrousable one hour after } \\
\text { returning from OR. } \\
\text { Approximately } 7 \mathrm{mg} \mathrm{PCA} \\
\text { morphine delivered RR of } 4 \text {. }\end{array}$ & $\begin{array}{l}\text { Oxygen, naloxone } \\
0.8 \mathrm{mg} \mathrm{i} \text {. }\end{array}$ \\
\hline 2 & 42 & $\mathbf{M}$ & $\begin{array}{l}\text { Appendicec- } \\
\text { tomy }\end{array}$ & None & 2 & 10 & 1 & None & $\begin{array}{l}\text { Confused and drowsy } \mathrm{SpO}_{2} \\
59 \% 24 \text { hr postop. Treated } \\
\text { with oxygen and background } \\
\text { stopped. } \mathrm{SpO}_{2} 68 \% \text { with oxy- } \\
\text { gen two hours later. ABG's } \\
\mathrm{PaO}_{2} 46, \mathrm{PaCO}_{2} 55, \mathrm{H}^{+} 55 \text {. }\end{array}$ & $\begin{array}{l}\text { Oxygen, naloxone } \\
0.4 \mathrm{mg} \text { in. }\end{array}$ \\
\hline 3 & 64 & $\mathbf{F}$ & $\begin{array}{l}\text { Total knee } \\
\text { replacement }\end{array}$ & None & 1.4 & 10 & 1 & Indomethacin & $\begin{array}{l}11.8 \mathrm{mg} \text { PCA morphine } \\
\text { during first four hours } \\
\text { postop. RR of } 4,6 \text { hours } \\
\text { postop. Very drowsy. }\end{array}$ & $\begin{array}{l}\text { Oxygen, naloxone } \\
0.1 \mathrm{mg} \text { im. } \\
\text { Increased RR to } \\
6-7 . \text { Easily } \\
\text { rousable. Bolus } \\
\text { decreased to } 1 \\
\text { mg and } \\
\text { background } \\
\text { stopped. }\end{array}$ \\
\hline 4 & 84 & $\mathbf{F}$ & $\begin{array}{l}\text { Hysterectomy } \\
\text { BSO, } \\
\text { omentec- } \\
\text { tomy }\end{array}$ & Age & 0.6 & 10 & None & None & $\begin{array}{l}\text { PCA morphine in } 6 \mathrm{mg} \text { in } \\
2 \mathrm{hr} \text { following return from } \\
\text { OR. RR of } 4 \text {. Difficult to } \\
\text { rouse. }\end{array}$ & $\begin{array}{l}\text { Oxygen, naloxone } \\
0.4 \mathrm{mg} \dot{\mathrm{N}} .\end{array}$ \\
\hline 5 & 85 & $\mathbf{F}$ & Colostomy & Age & 1 & 10 & None & None & $\begin{array}{l}\text { Morphine } 15 \mathrm{mg} i v \text { in OR and } \\
\text { PARR. PCA morphine } 6 \mathrm{mg} \\
\text { in first two hours after } \\
\text { returning from PARR. Found } \\
\text { drowsy with a RR of } 7 \text {. }\end{array}$ & $\begin{array}{l}\text { Oxygen, CPAP, } \\
\text { naloxone } 0.4 \mathrm{mg} \\
\text { iv. }\end{array}$ \\
\hline 6 & 27 & $\mathbf{M}$ & $\begin{array}{l}\text { Facial } \\
\text { fracture } \\
\text { awaiting } \\
\text { surgery }\end{array}$ & None & 2 & 8 & None & $\begin{array}{l}\text { Lorazepam } \\
1 \mathrm{mg} \mathrm{s.l.} \mathrm{at} \\
2400 \mathrm{hr}\end{array}$ & $\begin{array}{l}\text { Stable until } 2400 \mathrm{hr} \text {. PCA } \\
\text { morphine } 8-10 \mathrm{mg} \mathrm{q} 4 \mathrm{~h} \text {. No } \\
\text { PCA use after } 2400 \mathrm{hr} \text {. Found } \\
\text { obstructed and cyanotic. }\end{array}$ & $\begin{array}{l}\text { Oxygen, CPAP, } \\
\text { naloxone } 0.4 \mathrm{mg} \\
\dot{i} .\end{array}$ \\
\hline 7 & 56 & $\mathbf{M}$ & $\begin{array}{l}\text { Bilat. total } \\
\text { knee } \\
\text { replacement }\end{array}$ & $\begin{array}{l}\text { Probable sleep } \\
\text { apnoea. Not } \\
\text { diagnosed } \\
\text { preoperatively }\end{array}$ & 1 & 10 & None & None & $\begin{array}{l}\text { Required nasal airway postop. } \\
\text { Very sedated. Narcan } 0.1 \text { in } \\
\text { given and bolus decreased to } \\
0.6 \mathrm{mg} \text {. Bolus increased to } 1.0 \\
\text { mg at } 0700 \text { on following } \\
\text { morning. Found at } 1130 \text { not } \\
\text { rousable. } \mathrm{ABG}^{-} \mathrm{PaO}_{2} 76 \\
\mathrm{PaCO}_{2} 60, \mathrm{H}^{+} 53 \text {. }\end{array}$ & $\begin{array}{l}\text { Oxygen, naloxone } \\
0.4 \mathrm{mg} \text { iv. PCA } \\
\text { stopped. } \\
\text { Switched to } \\
\text { Ketorolac im. }\end{array}$ \\
\hline 8 & 27 & $\mathbf{M}$ & $\begin{array}{l}\text { Donor } \\
\text { nephrec- } \\
\text { tomy }\end{array}$ & None & 2 & 8 & None & None & $\begin{array}{l}\text { Found cyanotic with shallow } \\
\text { respirations } 24 \mathrm{hr} \text { postop. } \\
\text { PCA morphine } 20-30 \mathrm{mg} \\
\text { q4h for } 24 \mathrm{hr} \text {. }\end{array}$ & $\begin{array}{l}\text { Oxygen, naloxone } \\
0.4 \mathrm{mg} \text { i } 2 \\
\text { doses. PCA held. } \\
\text { Bolus decreased } \\
\text { to } 1 \mathrm{mg} \text { and } \\
\text { lockout } \\
\text { increased to } 12 \\
\text { min. }\end{array}$ \\
\hline
\end{tabular}


sia was discontinued and the patient required no further analgesics for $48 \mathrm{hr}$.

\section{Case \#3}

A 64-yr-old woman in general good health underwent a total knee replacement under general anaesthesia. During surgery and in the PARR the patient received fentanyl $75 \mu \mathrm{g}$ and morphine $21 \mathrm{mg} i \mathrm{i}$. Patient-controlled analgesia with morphine was ordered with a bolus dose of $1.4 \mathrm{mg}$ and a background infusion of $1 \mathrm{mg} \cdot \mathrm{hr}^{-1}$ which was started in the PARR. In addition, the patient received indomethacin $100 \mathrm{mg} \mathrm{pr}$ in the PARR. Five hours later the PCA was discontinued because of excessive sedation and a respiratory rate of 6-8 breaths $\cdot \mathrm{min}^{-1}$. Over the previous four hours the patient had received $11.8 \mathrm{mg}$ morphine via the PCA device, including approximately $5 \mathrm{mg}$ in the background infusion. Two hours later the patient was very drowsy and the respiratory rate had decreased to $4-5$ breaths $\cdot \mathrm{min}^{-1}$. The patient received naloxone 0.1 $\mathrm{mg} i \mathrm{~m}$ and the respiratory rate and level of consciousness improved considerably. Patient-controlled analgesia was restarted the following morning with a bolus of $1 \mathrm{mg}$ and no background infusion. The patient required morphine 2-3 mg every four hours to obtain satisfactory analgesia. No further problems were noted.

\section{Cases \#4 and 5}

Both patients were elderly women (aged 84 and $85 \mathrm{yr}$ ) who underwent laparotomies. Patient \#4 received morphine $19.5 \mathrm{mg}$ perioperatively before PCA, and an additional $6 \mathrm{mg}$ via PCA following her return to the ward. Patient \#5, who weighed $46 \mathrm{~kg}$, received morphine 15 $\mathrm{mg}$ perioperatively plus $6 \mathrm{mg}$ via PCA. Both patients were found to be very sedated and bradypnoeic (4-7 breaths $\cdot \min ^{-1}$ ) within two hours of returning to the wand. Both responded immediately to treatment with oxygen and intravenous naloxone. It should be noted that the relatively large doses of morphine administered perioperatively to both of these patients may have been partly responsible for the severe respiratory depression seen a short time later on the ward.

\section{Case $\# 6$}

An otherwise healthy 27 -yr-old man was admitted with a facial smash as a result of being kicked by a bull while participating in a rodeo. His medical history was unremarkable and he was taking no medications. There was no evidence of airway or cardiorespiratory compromise. His level of consciousness was normal and there was no suggestion of an intracranial injury. Before surgery he was ordered PCA morphine with a bolus of $2 \mathrm{mg}$, a lockout interval of eight minutes, and no background infusion.
During the day the patient was alert and stable. His morphine consumption was 8 to $10 \mathrm{mg} \mathrm{q} 4 \mathrm{hr}$. At midnight the patient received lorazepam $1 \mathrm{mg}$ po. From 0000 to $0320 \mathrm{hr}$ the patient received only $2 \mathrm{mg}$ of PCA morphine. At $0320 \mathrm{hr}$ the patient was found, during routine rounds, to be cyanotic with severe inspiratory obstruction, and a Glasgow coma score of 3 . He was promptly resuscitated with oxygen, an oropharyngeal airway, and CPAP. With this his $\mathrm{SpO}_{2}$ returned to normal immediately, but he did not regain consciousness. He then received naloxone $0.4 \mathrm{mg} i v$ and regained consciousness promptly. The patient made a full and immediate recovery. Patientcontrolled analgesia was discontinued, and $i m$ codeine ordered in its place. The following night, the patient received codeine $60 \mathrm{mg} i \mathrm{~m}$ plus lorazepam $1 \mathrm{mg}$, and again, the nurses noted that he was very sedated and partially obstructed whenever his head fell forward. With these episodes his recorded $\mathrm{SpO}_{2}$ decreased as low as $60 \%$. He was managed with close observation. The lorazepam was subsequently omitted. No further problems occurred.

\section{Case \#7}

A 56-yr-old man underwent bilateral total knee replacement under general anaesthesia. Postoperatively the patient was very sedated and required a nasal airway to maintain airway patency. Despite modest doses of morphine (16 mg over $12 \mathrm{hr}$ ) via PCA, the patient became very sedated and hypercapnic. On the morning of the first postoperative day the patient complained of pain unrelieved by bolus doses of morphine $0.6 \mathrm{mg}$. The bolus dose was increased to $1 \mathrm{mg}$, and four hours later the patient was found to be unrousable with inspiratory obstruction. Arterial blood gas analysis revealed $\mathrm{PaO}_{2} 76$ $\mathrm{mmHg}, \mathrm{PaCO}_{2} 60 \mathrm{mmHg}$, and $\left[\mathrm{H}^{+}\right] 53 \mathrm{nmol} \cdot \mathrm{L}^{-1}(\mathrm{pH}$ 7.27). On reviewing the patient's history, both before and during admission, it was concluded that the patient suffered from sleep apnoea syndrome. Patient-controlled analgesia was discontinued and the patient subsequently received im ketorolac for analgesia.

\section{Case \#8}

A healthy 27-yr-old man underwent an uneventful donor nephrectomy. Postoperatively, PCA morphine was initiated with a bolus dose of $2 \mathrm{mg}$, a lockout interval of eight minutes, and no background infusion. No other sedatives or opioids were administered. Over the first 24 $\mathrm{hr}$ postoperatively, the patient self-administered an average of 20-30 mg morphine every four hours. Approximately $24 \mathrm{hr}$ postoperatively the patient was found to be cyanotic with shallow respirations. He was treated with oxygen and naloxone $0.8 \mathrm{mg} i v$ with immediate recovery. Patient-controlled analgesia was withheld until the patient requested additional analgesia. The PCA bolus dose was 
decreased to $1 \mathrm{mg}$ and the lockout interval increased to $12 \mathrm{~min}$. Subsequent PCA requirements were minimal - 0-2 mg every four hours.

\section{Discussion}

In the population studied, the incidence of reported, severe respiratory depression associated with PCA was $0.5 \%$. This is less than that reported for im opioids $(0.9 \%),{ }^{5}$ but more than for intrathecal $(0.36 \%)$ and epidural opioids (0.09-0.2\%). ${ }^{3,4}$ These findings are in agreement with those of Fleming and Coombs ${ }^{1}$ who reported five cases of severe respiratory depression in 1122 postoperative patients receiving PCA and with those of MacIntyre et al. who found four cases among the 747 patients reviewed. ${ }^{2}$

The true incidence of respiratory compromise associated with postoperative opioid analgesia, regardless of the route of administration, may be higher than reported for two reasons. Firstly, studies that address this issue are based on retrospective chart reviews. There may be instances of sedation and/or presumed respiratory depression which are deemed to be severe but not dangerous by the physician or nurse; these may result in a change of therapy without mention of respiratory depression. Secondly, respiratory depression is usually defined as excessive sedation and/or bradypnoea. This definition does not consider the poor correlation between respiratory rate and $\mathrm{PaCO}_{2},{ }^{6}$ or the potentially serious problem of postoperative hypoxaemia. This problem is illustrated by Catley et al. ${ }^{7}$ who found that ten of 16 postoperative patients receiving $i v$ morphine infusions experienced multiple episodes of hypoxaemia (defined as $\mathrm{SaO}_{2}<80 \%$ ), not associated with bradypnoea. In addition, all episodes of hypoxaemia occurred during sleep, an obvious problem if sedation is part of the definition. Despite these problems in determining the true incidence of severe respiratory depression, the data suggest that PCA provided in the milieu of a comprehensive pain management service compares favourably with both traditional im and spinal opioids.

There are several factors contributing to the development of respiratory depression with PCA. Early reports $^{8-11}$ focused attention on operator errors such as misprogramming, and mechanical problems or malfunctions which led to overdoses of opioid. Recent studies ${ }^{1,12}$ have found that such serious errors are very uncommon. Pharmacokinetic factors including hypovolaemia ${ }^{13}$ and acute renal failure ${ }^{14}$ have also been cited. Hypovolaemia may result in higher initial serum concentrations and a slower early distribution phase, both of which will result in greater CNS concentrations of the drug. If hypovolaemia is associated with hypotension and hypoxaemia, CNS hypoxia may potentiate any opioid-induced respiratory de- pression. Prolonged hypovolaemia may decrease drug clearance. Administration of morphine or meperidine to patients with renal insufficiency may lead to the accumulation of active metabolites.

In this review problems included the concurrent use of background infusions (cases \#1-3), extremes of age (cases \#4 and 5), concomitant administration of additional sedative/hypnotics (case \#6), preexisting respiratory compromise (case \#7), and excessively liberal prescribing (case \#8).

\section{Background infusions}

The use of a background infusion with PCA is associated with a higher incidence of severe respiratory depression than is PCA alone. ${ }^{1,12}$ Although less than $10 \%$ of patients in the present study received a background infusion, $38 \%$ of the eight cases reported are in this group (see Table). Fleming and Coombs ${ }^{1}$ reported that three of five patients who developed severe respiratory depression and two of three patients who developed other major complications received background infusions, even though they were used in only $7 \%$ of the 1122 patients reviewed. Notcutt and Morgan ${ }^{12}$ cite a $2.5 \%$ incidence of respiratory complications in patients receiving background infusions, compared to $1 \%$ in those with PCA only.

Most studies fail to demonstrate any benefits when PCA is combined with a background infusion. ${ }^{15-18}$ Indeed, several studies have shown that opioid requirements are increased. ${ }^{15-17,19}$ Parker et al. ${ }^{18}$ found that three of 78 patients receiving a background infusion of morphine had prolonged episodes of postoperative hypoxaemia when monitored with continuous pulse oximetry, compared with no episodes of hypoxia in patients receiving PCA alone. Even those who advocate the use of background infusions do so cautiously, recommending low hourly infusion rates or a lower hourly limit to PCA. ${ }^{20,21}$ Patients for whom background infusions may be indicated include patients with a preexisting or demonstrated opioid tolerance.

\section{$P C A$ in the elderly}

The safe and effective use of PCA by the elderly is often difficult. Pharmacodynamic and pharmacokinetic changes are in part responsible. ${ }^{22}$ Elderly patients are more susceptible to a given serum concentration of opioid and sedative medications. ${ }^{22}$ In addition, a lower initial volume of distribution and reduced protein binding may potentiate the effect of an initial bolus dose. Clearance of drugs by the kidney and liver is reduced, and the volume of distribution of lipophilic drugs may increase with age because of an increased percentage of body fat; the result is an increased elimination half-life. The greatest impediment to the use of PCA by the elderly is the in- 
ability of some patients to comprehend and remember the instructions for its safe use. For patients unable to use PCA a carefully titrated continuous infusion (instead of PCA) may be more appropriate; such patients must be closely monitored. Other alternatives include oral and rectal administration of non-opioid analgesics (including non-steroidal anti-inflammatory drugs and acetaminophen), spinal opioids, and local anaesthetics.

\section{Concomitant sedative medications}

Case \#6 describes a patient who remained stable while receiving PCA alone, but who suffered a near respiratory arrest following the concomitant administration of lorazepam $1 \mathrm{mg}$ po for night-time sedation. The respiratory depressant effects of benzodiazepines and opioids in combination are additive, if not synergistic. ${ }^{23,24}$ Sedative/hypnotic medications are not generally necessary, and should be ordered only for specific indications. A simple sleep disturbance is typical for the first one or two nights postoperatively, and is not an indication for $h s$ sedation. It is important to ensure that only those individuals responsible for PCA orders are permitted to order additional sedative/hypnotic medications. Patients who may benefit from benzodiazepines (or other sedative/hypnotics) include those with a preexisting dependence on these or other sedative medications (e.g., alcohol) and those in whom anxiety compromises the effectiveness of PCA. If a patient is to receive benzodiazepines with PCA, it is prudent to stop any background infusion, increase the lockout interval, and administer supplemental oxygen until the response to treatment can be assessed.

\section{Opioid analgesia and sleep apnoea}

The management of postoperative pain in the patient with known or suspected sleep apnoea is challenging. Effective analgesia is necessary to facilitate coughing, physiotherapy, and ambulation, particularly following thoracic or upper abdominal surgery. The subjective impression of the author and others 25,26 is that these patients are at increased risk of severe hypoventilation and hypoxia, even with modest doses of opioids. The first steps in management are to ensure that the patient is monitored adequately and receives supplemental oxygen postoperatively. Monitoring should include continuous pulse oximetry with constant care nursing or admission to the intensive care unit in the early postoperative period. Supplemental oxygen therapy may best be given via nasal continuous positive airway pressure. The optimal choice of analgesia is controversial. ${ }^{29}$ The author prefers to provide continuous epidural analgesia with repeated injections of morphine. PCA is an alternative. Unless contraindicated, regularly administered non-steroidal antiinflammatory drugs are provided as an adjunct to the opioids; the opioid-sparing effect of these drugs may reduce the incidence of respiratory depression. ${ }^{27,28}$ (Note that this hypothesis is unproven.)

\section{Appropriate PCA bolus doses and lockout intervals}

Case \#8 presents a young healthy patient who developed severe respiratory depression $24 \mathrm{hr}$ postoperatively. The PCA bolus dose of morphine $2 \mathrm{mg}$ and lockout interval of eight minutes were within suggested limits, ${ }^{30,31,24}$ yet the patient clearly received a relative overdose of medication (20-30 mg every four hours). This dosing schedule permitted the patient to self-administer up to $15 \mathrm{mg}$ of morphine per hour; in the absence of preexisting opioid tolerance, this was clearly excessive.

The goals of PCA are to provide effective analgesia without overdose. To do this, a single bolus dose should be large enough to provide analgesia. The lockout period should be short enough to allow another dose when necessary, yet long enough to protect the patient from excessive administration. These variables will be affected by the patient's preoperative status, the surgical procedure, and the use of adjuvant analgesic therapy. In the author's experience, most patients do well with a bolus of morphine $1 \mathrm{mg}$ and a lockout interval of ten minutes. A minority of patients obtain inadequate relief with a $1 \mathrm{mg}$ bolus; for these patients increasing the bolus to $2 \mathrm{mg}$ and increasing the lockout interval to $15 \mathrm{~min}$ usually provides effective analgesia with a reasonable hourly limit. This practice is supported by Owen et al. ${ }^{32}$ who found that a bolus dose of morphine $1 \mathrm{mg}$ with a fiveminute lockout provided satisfactory analgesia for patients undergoing laparotomy; a bolus of $2 \mathrm{mg}$ resulted in greater morphine consumption with the development of severe respiratory depression in four of seven patients.

\section{Conclusions}

When PCA is used appropriately, the incidence of severe respiratory depression compares favourably with opioid administration by other routes. However, complications do occur, and a single death is too many. How, then, may we avoid such a disaster? This paper has focused on the problems of concurrent background infusions, PCA in the elderly, preexisting respiratory compromise, concomitant administration of sedative/hypnotic medications, and excessively liberal PCA dosing schedules. In all of the cases presented there is an identifiable contributing factor. Knowing these contributing factors allows us to modify our treatment strategies in the future and further reduce the incidence of serious problems.

For patients perceived to be at increased risk, supplemental oxygen therapy is safe and inexpensive. Occasional patients may warrant the use of continuous pulse oximetry and/or constant care nursing. Opioid-sparing 
strategies, especially the adjunctive use of non-steroidal anti-inflammatory drugs (NSAIDs) may be beneficial, ${ }^{27}$ but the evidence that less opioid consumption equates with less respiratory depression is limited. ${ }^{28}$ Often it is the postoperative patient with a preexisting increased risk of respiratory depression who has the most to gain from effective analgesia. For many of these patients PCA remains a practical approach to pain management, albeit with a conservative dosing schedule, attentive monitoring, and more frequent reassessment. ${ }^{25}$

To date we have not suffered any serious mishaps due to operator error. This we attribute in part to a welldeveloped administrative infrastructure. This infrastructure has facilitated education of the nursing and medical staff and the development of specific nursing policies and procedures. Because a dedicated anaesthetist is responsible for the acute pain service on a weekly basis, there are frequent patient reassessments and continuity of care.

Patient-controlled analgesia, used properly, is safe and effective. However, there is little evidence that it reduces morbidity or the cost of hospitalization, ${ }^{33,34}$ and there is no evidence that the risk of serious respiratory depression is less than that seen with epidural opioid administration. At present the only proven benefits of PCA compared with traditional pm im opioids are greater patient comfort and patient satisfaction. At our institution we have had no deaths or persistent morbidity attributable to PCA. Others have been less fortunate. ${ }^{35}$ Our current enthusiasm for the benefits of PCA must be tempered by our knowledge of the potential risks.

\section{References}

1 Fleming BM, Coombs DW. A survey of complications documented in a quality-control analysis of patientcontrolled analgesia in the postoperative patient. Journal of Pain and Symptom Management 1992; 7: 463-9.

2 Macintyre PE, Runciman WB, Webb RK. An acute pain service in an Australian teaching hospital: the first year. Med J Aust 190; 153: 417-21.

3 Rawal N, Arnér S, Gustafsson LL, Allvin R: Present state of extradural intrathecal and opioid analgesia in Sweden. Br J Anaesth 1987; 59: 791-9.

4 Ready BL, Loper KA, Nessly M, Wild L. Postoperative epidural morphine is safe on surgical wards. Anesthesiology 1991; 75: 452-6.

5 Miller $R$. Analgesics. In: Miller RR, Greenblatt DJ (Eds.). Drug Effects in Hospitalized Patients. New York: John Wiley and Sons, 1976: 133-64.

6 Etches $R C$, Sandler $A N$, Daley $M D$. Respiratory depression and spinal opioids. Can J Anaesth 1989; 36: 165-85.

7 Catley DM, Thornton C, Jordan C, Lehane JR, Royston $D$, Jones JG. Pronounced, episodic oxygen desaturation in the postoperative period: its association with ventilatory pattern and analgesic regimen. Anesthesiology 1985; 63: 20-8.

8 White $P F$. Mishaps with patient-controlled analgesia. Anesthesiology 1987; 66: 81-3.

9 Notcutt $W G$, Knowles $P$, Kaldas $R$. Overdose of opioid from patient-controlled analgesia pumps. $\mathrm{Br} J$ Anaesth 1992; 69: 95-7.

10 Christie JM, Greenstein AS, Rafii A. A respiratory arrest with patient controlled analgesia. Anesthesiol Rev 1990; 17 : 45-8.

11 Thomas $D W$, Owen $H$. Patient-controlled analgesia - the need for caution. Anaesthesia 1988; 43: 770-2.

12 Notcutt WG, Morgan RJM. Introducing patientcontrolled analgesia for postoperative pain control into a district general hospital. Anaesthesia 1990; 45: 401-6.

13 Owen $H$, White PF. Patient-controlled analgesia: an overview. In: Sinatra RS, Hord AH, Ginsberg B, Preble LM (Eds.). Acute Pain: Mechanisms and Management. St. Louis: Mosby-Yr Book, 1992: 151-64.

14 Geller RJ. Meperidine in patient-controlled analgesia: a near-fatal mishap. Anesth Analg 1993; 76: 655-7.

15 Hansen $L A$, Noyes MA, Lehman ME. Evaluation of patient-controlled analgesia (PCA) versus PCA plus continuous infusion in postoperative cancer patients. Journal of Pain and Symptom Management 1991; 6: 4-14.

16 Owen H, Szekely SM, Plummer JL, Cushnie JM, Mather $L E$. Variables of patient-controlled analgesia. 2. Concurrent infusion. Anaesthesia 1989; 44: 11-3.

17 Parker RK, Holtmann B, White PF. Patient-controlled analgesia: does a concurrent opioid infusion improve pain mangement after surgery? JAMA 1991; 266: 1947-52.

18 Parker RK, Holtmann B, White PF. Effects of a nighttime opioid infusion with PCA therapy on patient comfort and analgesic requirements after abdominal hysterectomy. Anesthesiology 1992; 76: 362-7.

$19 W u$ MYC, Purcell GC. Patient-controlled analgesia: the value of a background infusion (Letter). Anaesth Intensive Care 1990; 18: 575-6.

20 McCoy EP, Furness G, Wright PMC. Patient-controlled analgesia with and without background infusion. Analgesia assessed using the demand:delivery ratio. Anaesthesia 1993; 48: 256-65.

21 Sinatra $R$, Chung KS, Silverman DG, et al. An evaluation of morphine and oxymorphone administered via patientcontrolled analgesia (PCA) or PCA plus basal infusion inpostcesarean-delivery patients. Anesthesiology 1989; 71: 502-7.

$22 \mathrm{McLeskey} \mathrm{CH}$. Anesthesia for the geriatric patient. In: Barash PG, Cullen BF, Stoelting RK (Eds.). Clinical Anesthesia. 2nd ed. Philadelphia: J.B. Lippincott, 1992; 1353-88.

23 Van den Hoogen RHW, Bervoets KJW, Colpaert FR. Respiratory effects of epidural morphine and sufentanil in 
the absence and presence of chlordiazepoxide. Pain 1989; 37: 103-10.

24 Ready LB, Edwards WT. Management of Acute Pain: A Practical Guide. International Association for the Study of Pain. Seattle, WA: 1ASP Publications, 1992.

25 VanDercar DH, Martinez AP, De Lisser EA. Sleep apnea syndromes: a potential contraindication for patientcontrolled analgesia. Anesthesiology 1991; 74: 623-4.

26 Tierney NM, Pollard BJ, Doran BRH. Obstructive sleep apnoea. Anaesthesia 1989; 44: 235-7.

27 Dahl JB, Kehlet $H$. Non-steroidal anti-inflammatory drugs: rationale for use in severe postoperative pain. $\mathrm{Br} \mathrm{J}$ Anaesth 1991; 66: 703-12.

28 Perttunen K, Kalso E, Heinonen J, Salo J. I.V. diclofenac in post-thoracotomy pain. $\mathrm{Br} \mathrm{J}$ Anaesth 1992; 68: 474-80.

29 Gwirtz $K H$. Single-dose intrathecal opioids in the management of acute postoperative pain. In: Sinatra RS, Hond AH, Ginsberg B, Preble LM. (Eds.). Acute Pain: Mechanisms and Management. St. Louis, MO: Mosby Yr Book, 1992.

30 Ferrante FM. Patient-controlled analgesia. In: Sandler AN (Guest Editor.). Current Concepts in Acute Pain Control. Philadelphia, PA: W.B. Saunders Company, 1992; 287-98.

31 White $P F$. Use of patient-controlled analgesia for management of acute pain. JAMA 1988; 259: 243-7.

32 Owen H, Plummer $J$, Armstrong I, Mather LE, Cousins MJ. Variables of patient-controlled analgesia: 1. Bolus size. Anaesthesia 1989; 44: 7-10.

33 Ready LB. Patient-controlled analgesia - does it provide more than comfort? Can J Anaesth 1990; 37: 719-21.

34 Angel JM, McKay WR. PCA and postsurgical outcome: influence on morbidity and length of hospital stay. In: Sinatra RS, Hord AH, Ginsberg B, Preble LM (Eds.). Acute Pain: Mechanisms and Management. St. Louis, MO: Mosby Yr Book, 1992; 201-4.

35 Grey TC, Sweeney ES. Patient-controlled analgesia (Letter). JAMA 1988; 259: 2240. 